\title{
Estrogen receptor-related receptors: orphan receptors desperately seeking a ligand
}

\author{
B Horard and J-M Vanacker \\ Laboratoire de Biologie Moléculaire de la Cellule, CNRS UMR 5161, Ecole Normale Supérieure de Lyon, 46 allée d'Italie, 69364 Lyon, France \\ (Requests for offprints should be addressed to J-M Vanacker; Email: jmvanack@ens-lyon.fr)
}

\begin{abstract}
The nuclear receptor family comprises ligand-dependent and orphan receptors. To the latter group belong the estrogen receptor-related receptors (ERRs) for which conflicting results have been published concerning the nature (constitutive or liganded) of their transcriptional activities. ERRs interfere in various ways, positively and negatively, with estrogen signaling. Moreover recent data analyzing ERR expression in human breast tumors have proposed ERR $\alpha$ and ERR $\gamma$ as prognostic markers of these cancers. The identification of modulators (positive or negative) of ERR activities would therefore be highly useful in our understanding of estrogen-related pathologies. The purpose of this review is to summarize our knowledge of the nature of ERR activities and progresses in identifying synthetic ERR modulators.
\end{abstract}

Journal of Molecular Endocrinology (2003) 31, 349-357

\section{On nuclear receptors (NRs) in general and orphan receptors in particular}

According to a commonly used definition, NRs are described as ligand-dependent transcription factors (Laudet \& Gronemeyer 2002). With very few exceptions, all NR proteins share a similar organization in modular domains, two of which are remarkably conserved between members of the family and across evolution. These are (i) the DNA-binding domain (DBD), localized in the middle of the primary structure and which mediates specific interaction with the target DNA sequences and (ii) the ligand-binding domain (LBD), in the C-terminal part, which is responsible for ligand recognition, dimerization, interaction with coactivators and ligand-dependent transcriptional activation. Three-dimensional (3D) structure determination has demonstrated that ligand entry into the binding pocket of the LBD evokes a conformational change allowing the recruitment of coactivator proteins that directly or indirectly modify chromatin and induce target gene expression. Several coactivators have been described that interact with NRs, the most common being the three widely expressed p160 family members, SRC-1, GRIP1/TIF/SRC-2 and pCIP/AIB1/ SRC-3 (reviewed in McKenna et al. 1999). A ligand-independent transactivation domain can be found in the non-conserved N-terminal part (A/B domain) of certain, but not all, NRs, such as the estrogen receptor (ER) $\alpha$ (Laudet \& Gronemeyer 2002).

Receptors for classic ligands such as steroid hormones, thyroid hormones, retinoic acids or vitamin $\mathrm{D}$ were identified on the basis of their capacity to transduce a previously known hormonal signal. Besides them, the NR superfamily also comprises a number of so-called orphan receptors that were isolated on the basis of their sequence similarity and identical domain organization to other NRs (Giguère 1999). Since no ligand has been identified that regulates them, the orphan receptors do not fulfill the above-mentioned definition. One of the remaining questions concerning orphan receptors is how their transcriptional activities are regulated. In other words, do they respond to a natural ligand which remains 
to be identified, or do they act in a ligandindependent manner?

This question has been at least partially answered for a number of orphan receptors. For instance, certain oxysterols (catabolites of cholesterol) have been shown to act as ligands for LXRs, and to modulate (positively in rodent, negatively and indirectly in humans) the expression of an enzyme (Cyp7a) that catalyzes their degradation, thereby acting in a feed-forward mechanism (reviewed in Repa \& Mangelsdorf 2000, Goodwin et al. 2003). The LXRs can therefore be considered as ligand-dependent receptors. On the contrary 3D structure determination of Rev-erba has demonstrated that the putative ligand-binding pocket was actually packed with amino acid side-chains rendering the entry of a ligand very unlikely (Renaud et al. 2000). Rev-erba, which is in fact a transcriptional repressor, is therefore considered as a non-liganded, constitutively acting receptor. However, it should be remembered that a constitutive activity does not exclude the existence of a ligand, as exemplified by CAR. Indeed, the activity of this receptor, originally described as constitutive, can be down-regulated by androstane metabolites (Forman et al. 1998), but also further activated by phenobarbital (Tzameli et al. 2000).

In spite of the examples quoted above, there are some orphan receptors for which the existence of a ligand is still an open question. Although they were the first orphan receptors to be identified, this is the case for the estrogen-receptor related receptors (ERRs), to which this review is dedicated. Furthermore, even if a receptor is recognized as constitutively active, it could still be (at least theoretically) possible to modulate its activity using a synthetic agonist or antagonist. In this respect, recent data have identified synthetic antagonists of the ERRs. Given the wide variety of developmental, physiological and metabolic processes controlled by NRs, finding a way to modulate the activity of these transcription factors is an issue of considerable importance.

\section{On ERRs}

ERR $\alpha$ and $\beta$ were isolated in 1988 by mean of a low-stringency screen with the DBD of ER $\alpha$ (Giguère et al. 1988). More recently, a third member of the subfamily (ERR $\gamma)$ has been identified (Hong et al. 1999). ERRs are present throughout evolution, with a unique homologue existing in the invertebrates Drosophila, amphioxus and tunicates (Dehal et al. 2002, B Horard \& J-M Vanacker, unpublished observations). In terms of sequence, ERRs are fairly similar to the ERs (Fig. 1), particularly in the DBD regions (over $60 \%$ sequence identity between human $\operatorname{ERR} \alpha$ and $\mathrm{ER} \alpha$ ). The lower conservation level of the LBDs (less than 35\%) is apparently consistent with the incapacity of ERRs to bind estradiol (E2) (Giguère et al. 1988, Yang et al. 1996). However, in silico superimposition of the ligand-binding pocket of $\mathrm{ERR} \alpha$ on that of $\mathrm{ER} \alpha$ has revealed a greater level of local sequence identity, suggesting that structurally close ligands could be bound by both receptors (Chen et al. 2001).

In the past years, numerous interconnections between the ERRs and estrogen signaling have been documented, and these are thoroughly discussed in a recently published review (Giguère 2002) (see Fig. 2 for summary). For instance, ERRs and ERs share common transcriptional target genes, such as lactoferrin, osteopontin and pS2, on which they can either synergize or compete with one another (Yang et al. 1996, Vanacker et al. 1999a, Lu et al. 2001, Kraus et al. 2002). Furthermore, Yang et al. (1996) found that human $\mathrm{ERR} \alpha$ interacts with human $\mathrm{ER} \alpha$ at least in vitro through protein-protein contacts. Moreover, the aromatase gene, encoding the enzyme catalyzing the conversion of androgens to estrogens, is a transcriptional target of ERR $\alpha$ (Yang et al. 1998). Altogether, these finding have raised the possibility that the ERRs (at least ERR $\alpha$ ) might directly and indirectly modulate the estrogenic response.

Little is known about the in vivo functions of the ERRs. It has been proposed that ERR $\alpha$ plays a role in bone formation. Indeed this receptor is expressed in ossification zones of the mouse embryo (Bonnelye et al. 1997a) and up-regulates the expression of the osteopontin gene (Vanacker et al. 1998) coding for an extracellular matrix protein involved in bone remodeling. More recently, Bonnelye et al. (2001) have found that ERR $\alpha$ plays a role in in vitro osteoprogenitor cell proliferation and differentiation. Both ERR $\alpha$ and ERR $\gamma$ are also highly expressed in muscle, heart and adipose tissues (Bonnelye et al. 1997b, Hong et al. 1999, Heard et al. 2000). In adipose tissues, ERR $\alpha$ has been suggested to participate in the control of 


\section{DBD LBD}

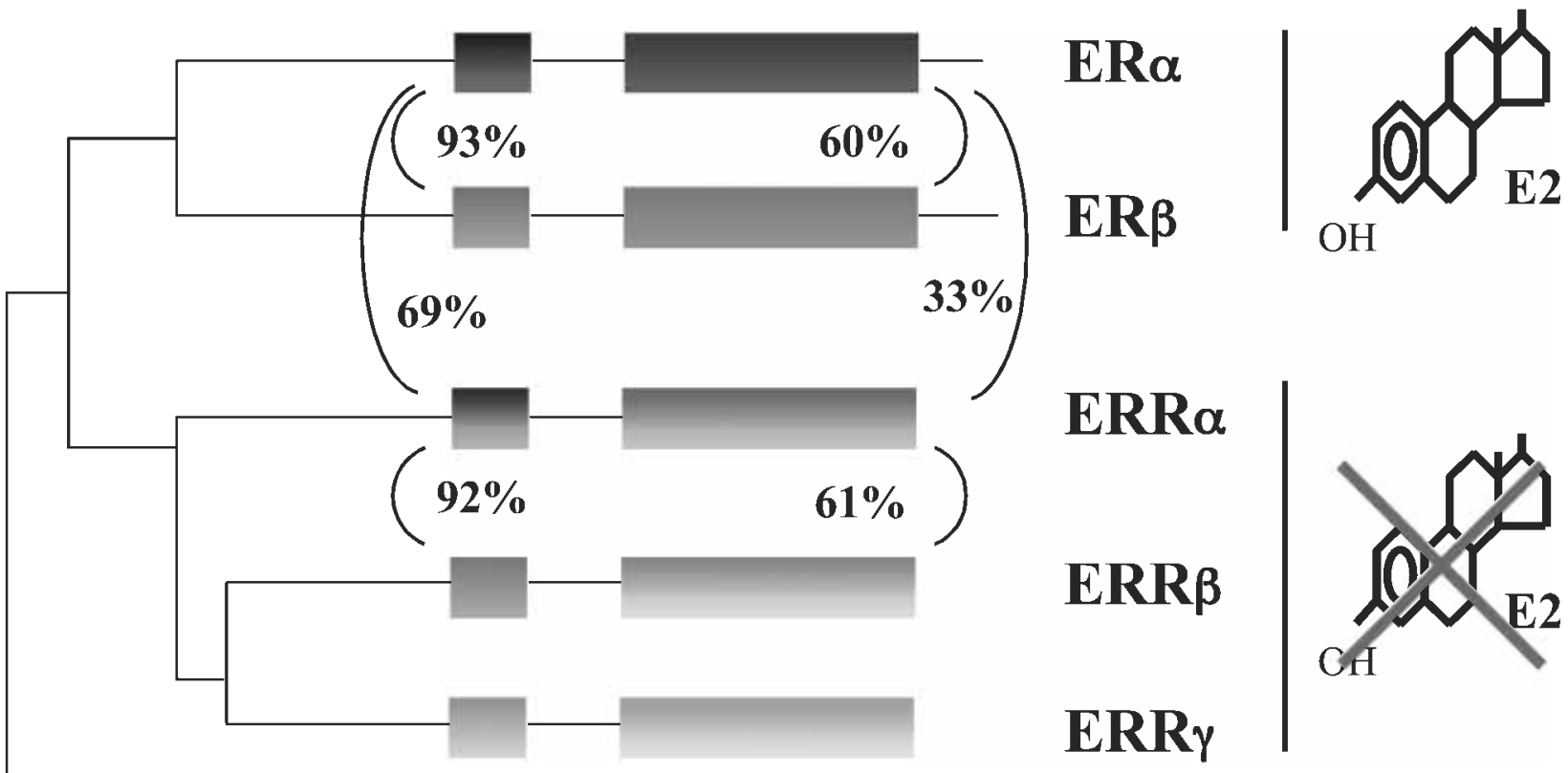

Figure 1 The ER/ERR subfamily A schematic representation of the two mouse ERs and the three mouse ERRs is displayed. Percentage of sequence identity within the DBD and the LBD is indicated.

energy expenditure through the regulation of the expression of the MCAD (medium-chain acyl dehydrogenase) gene (Sladek et al. 1997, Vega \& Kelly 1997). In the central nervous system, both ERR $\alpha$ and ERR $\gamma$ possess a complex pattern of expression (Bonnelye et al. 1997b, HermansBorgmeyer et al. 2000, Lorke et al. 2000) but no function has yet been attributed to the receptors. ERR $\beta$ is mainly expressed during early mouse development (Pettersson et al. 1996) where it is necessary for proper trophoblastic cell proliferation and differentiation as demonstrated by the placentation defects observed in mice lacking $\operatorname{ERR} \beta$ (Luo et al. 1997).

\section{A natural ligand for ERRs?}

ERRs bind as homodimers to at least two types of target DNA sequence, the estrogen response element (ERE: AGGTCAnnnTGACCT) and an extended half site originally characterized as SF1 (steroidogenic factor 1, another orphan
NR) response element (SFRE: TGAAGGTCA) (Pettersson et al. 1996, Bonnelye et al. 1997a, Johnston et al. 1997, Hong et al. 1999, Vanacker et al. 1999b, Hentschke et al. 2002a). Transcriptional activation through each of these sites occurs in an apparent ligand-independent manner as no external compound needs to be added to the culture medium. However, at least in the case of ERR $\alpha$, these transcriptional activities are exerted in a cell-specific manner (Bonnelye et al. 1997b). This could indicate the requirement for a ligand present in the permissive cells and not in the restrictive ones. In support of this hypothesis, rat osteosarcoma ROS 17.2/8 cells cultured for 2 weeks with charcoal-treated serum (i.e. depleted of lipophilic compounds including hormones) do not support ERR-driven transcriptional activation in contrast to cells cultured in normal medium (Vanacker et al. 1999b). However, since the normal medium could promote ligand-unrelated events (e.g. activating phosphorylation cascades), identification of the active compound will be necessary in order to conclude that a ligand exists. 


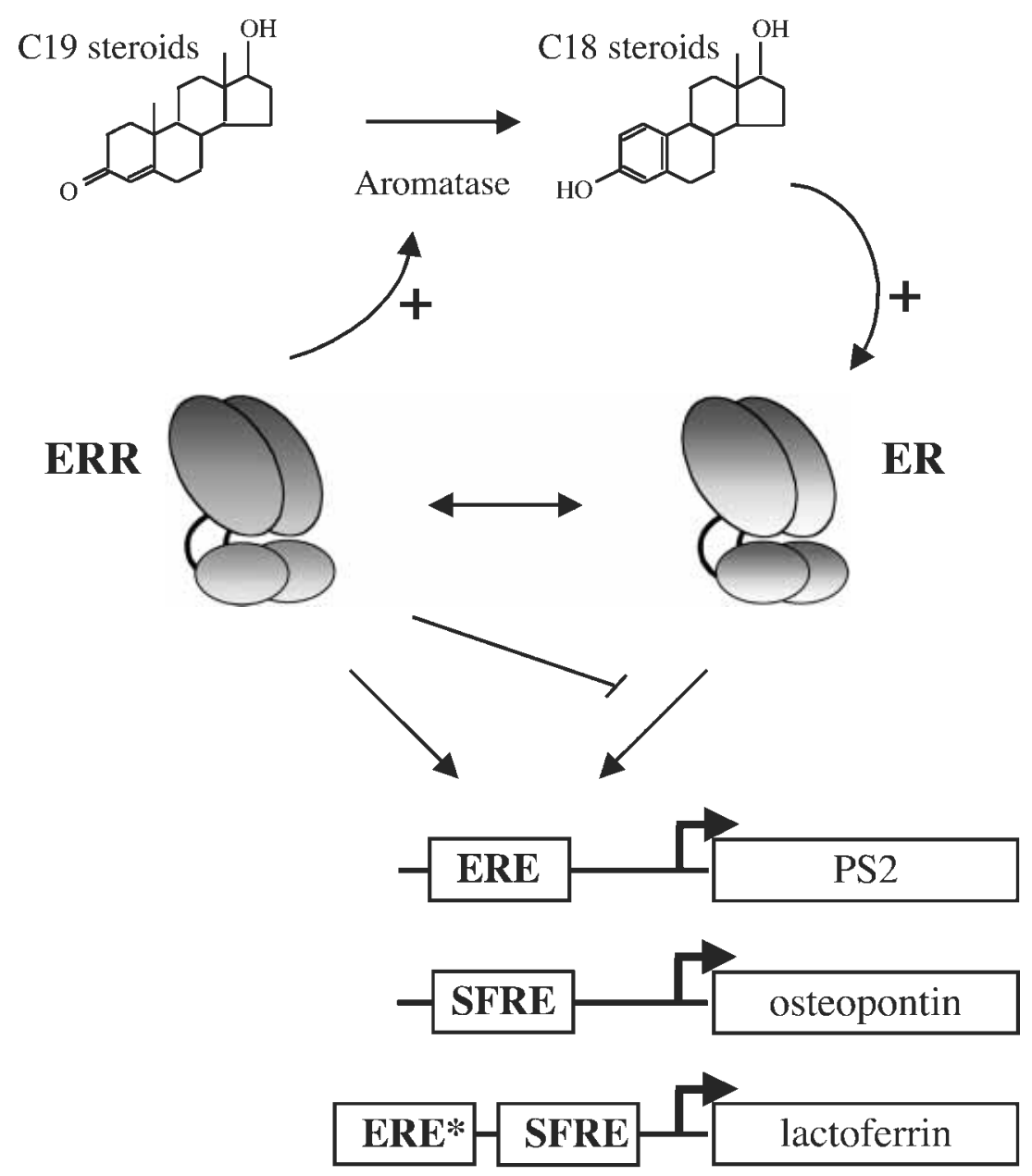

Figure 2 Interconnections between ER and ERRs. Interplay between ER and ERR includes physical contacts and transcriptional regulation of common target genes. Examples of such are the pS2 gene, osteopontin and lactoferrin, on which a perfect SFRE and an imperfect ERE (ERE*) have been identified. ERR can act as a transcriptional regulator per se or compete with ER for common binding sites. ERR also regulates the expression of the aromatase gene, whose product converts C19 (androgens) to C18 (estrogens) steroids such as estradiol-17 $\beta$, the most active natural ER ligand.

Alternatively the cell-dependent transcriptional activities of the ERRs could also reflect the presence or absence of a specific transcriptional coactivator. In this respect, ERRs have recently been shown to interact with members of the PGG-1 coactivator family (Hentschke et al. 2002b, Huss et al. 2002, Ichida et al. 2002, Schreiber et al. 2003), the expression of which is restricted to certain tissues and cells (Puigserver et al. 1998, reviewed in Knutti \& Kralli 2001). Orphan ERRs can also be coactivated by the widely expressed members of the p160 family, at least in transient transfection assays (Hong et al. 1999, Xie et al. 1999, Zhang \& Teng 2000). Whether this is also true in vivo remains to be investigated. In vitro experiments have demonstrated that interactions between ERR proteins and coactivators do not require the addition of any external compound. Since, in the case of classic receptors, this type of interaction is liganddependent, this suggests that ERRs are constitutive transcription factors. Nevertheless it cannot be formally excluded that a ligand is present and 
incorporated when the ERRs are translated in vitro or in bacteria. In this respect, the presence of certain fatty acids in the ligand-binding pocket of bacterially synthesized RAR (retinoic acid receptor) has been demonstrated by 3D structure determination (Bourguet et al. 2000). As a consequence, RAR is locked in an active conformation by the fatty acid moiety, which acts as a ligand. On the contrary, 3D structure determination of the LBD of ERR $\gamma$ has shown that this domain spontaneously (i.e. without any fortuitous ligand) adopted an active conformation (Greschik et al. 2002). These experiments have revealed the existence of a hydrophobic pocket that is, to date, the smallest one identified in NRs (roughly half the volume of that of $\mathrm{ER} \alpha$ ). As a consequence, putative agonist ligands that could further stabilize ERR $\gamma$ in an active conformation should be smaller that half the size of E2. However, the reduced size of the hydrophobic cavity does not seem to be the major determinant of ERR $\gamma$ 's constitutive activity. Mutants displaying an enlarged putative ligandbinding pocket (i.e. in which protruding amino acid side-chains were removed) are still transcriptionally active in a ligand-independent manner. Noteworthy, some of these mutants bind E2 but are not regulated by this hormone. Altogether this suggests that the overall LBD structure contributes to the spontaneous active conformation.

Crystallographic structures of $\operatorname{ERR} \alpha$ and $\operatorname{ERR} \beta$ have not been determined. The close sequence proximity of ERR $\beta$ and ERR $\gamma$ suggests identical transcriptional properties for both receptors (i.e. ligand-independence). ERR $\alpha$ 's LBD is more divergent. Computer-assisted modeling has been performed for this receptor using its similarity to $\mathrm{ER} \alpha$ (Chen et al. 2001). A striking difference is the presence of a phenylalanine side-chain across the binding pocket of ERR $\alpha$ where an alanine is found in $\operatorname{ER} \alpha$. The phenylalanine residue is thought to lock the LBD in an active conformation, since mutating this residue to an alanine results in a dominant negative mutant. This finding has also led to the conclusion that no steroid ligand (E2 in particular) could enter the binding pocket. However, ligands can adapt to the particular constraints of a given ligand-binding pocket. This is, for instance, the case for 9-cis retinoic acid that adopts different conformations when bound to RAR $\gamma$ or retinoid $\mathrm{X}$ receptor $\alpha$ (Egea et al. 2000). Furthermore, the above-mentioned phenylalanine residue is not conserved throughout evolution: the single amphioxus ERR and the zebrafish ERR versions bear an alanine at the equivalent position (P-L Bardet, B Horard \& J-M Vanacker, unpublished observations). These receptors act as bona fide transcription activating factors and in spite of a greater proximity to ER $\alpha$ 's LBD, these ERR orthologs are still not activated by E2.

What could be the nature of an eventual endogenous agonist ligand of ERRs, in particular of $\operatorname{ERR} \alpha$, for which the question is more open that for $\operatorname{ERR} \beta / \gamma$ ? The expression of aromatase, which converts C19- to C18-steroids, is stimulated by ERR $\alpha$. It could be that this up-regulation is necessary to clear the cells from an unwelcome compound by enhancing its degradation. By analogy with the rodent LXR, whose potentially toxic ligands promote their own degradation by activating the expression of a catabolic enzyme (reviewed in Repa \& Mangelsdorf 2000), one can imagine that a substrate (or precursor thereof) of the aromatase could act as an ERR $\alpha$ ligand, a hypothesis which remains to be tested.

\section{Synthetic ligands for ERRs}

Reports have been published identifying synthetic modulators of the activities of the ERRs. Strikingly, all these compounds are more or less connected to estrogen signaling and repress ERRs' transcriptional activities. They can be thus considered as antagonists (if ERRs possess natural ligands) or inverse agonists (if ERRs' transcriptional activities are truly constitutive). Two organic pesticides, toxaphene and chlordane, are indeed endocrine disrupters that can display weak estrogen-like activities. Both these molecules have been shown to down-modulate the transcriptional activities of ERR $\alpha$, probably by impairing its interactions with coactivators such as GRIP1 (Yang \& Chen 1999).

\section{Diethylstilbestrol (DES)}

DES, a synthetic estrogen, was widely used between the 1940s and the 1970s to prevent spontaneous abortion in women. However, patients exposed in utero to high doses of DES have a range of gynecological troubles, including a higher incidence of vaginal cancers and malformations of the reproductive tract. These phenotypes closely 


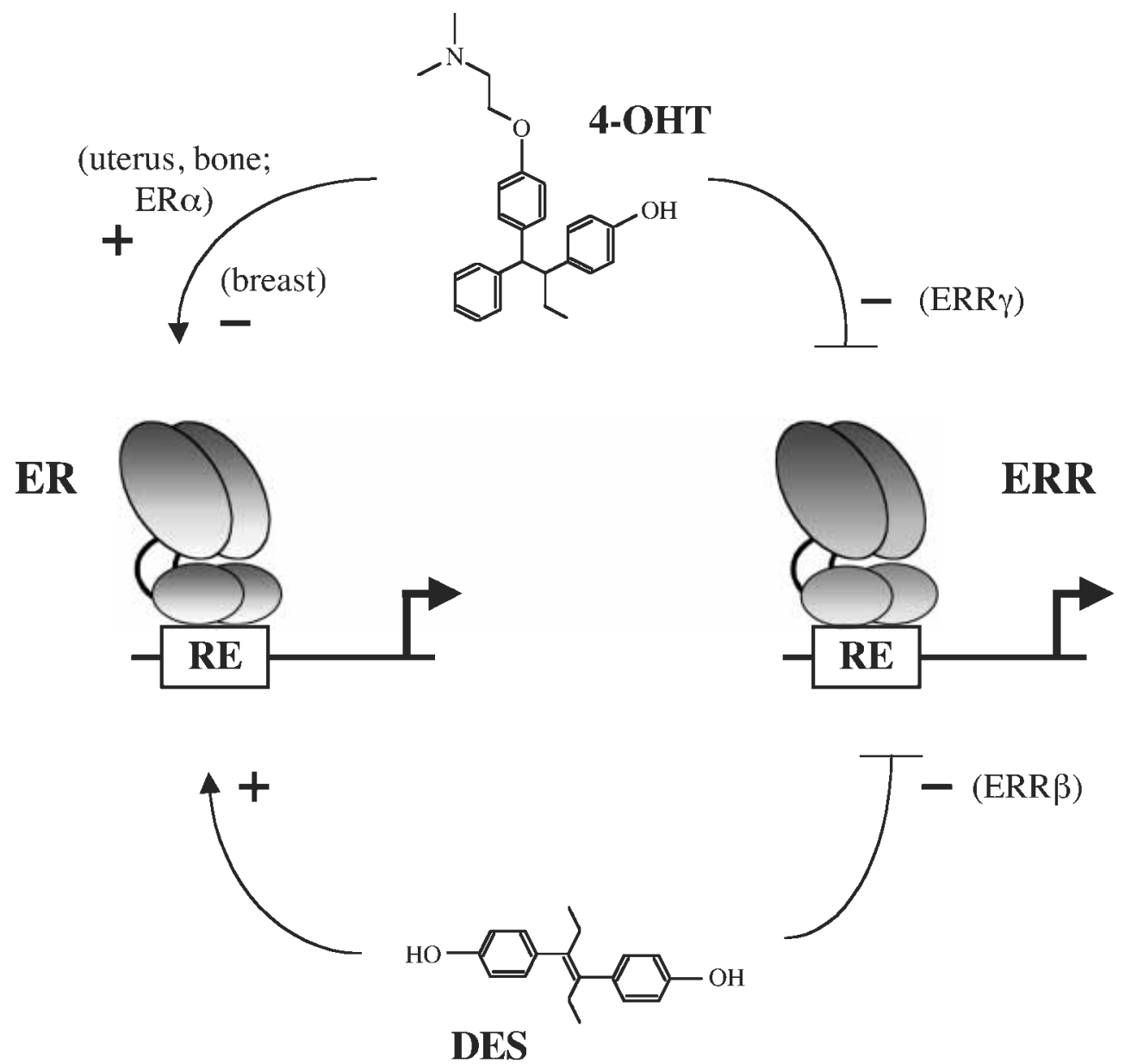

Figure 3 Contrasting effects of SERMs on ERs and ERRs. 4-OHT activates ER $\alpha$ in the uterus and bone, but acts as an estrogen antagonist in breast. 4-OHT also deactivates ERR $\gamma$. DES is a potent ER agonist and inhibits ERR $\beta$ 's transcriptional activities.

RE: response element. References are given in the text.

resemble those observed in null mouse models of some Wnt gene family members (Miller \& Sassoon 1998, Parr \& McMahon 1998). These data raised the proposition that disruption of developmental gene expression accounts for the DES syndrome. On this line, it was effectively shown that DES represses the expression of Wnt7a when administered perinatally (Miller et al. 1998). DES is a potent estrogen agonist, it can therefore be intuitively thought to act through ER and mimic the broad spectrum of E2 action. This view has recently been challenged by the finding that DES also represses the molecular activities of ERRs (Fig. 3 ), such as interaction with a coactivator fragment and reporter gene transactivation (Tremblay et al.
2001). Furthermore, administration of DES to pregnant mice partially phenocopies the absence of ERR $\beta$, resulting in an absence of labyrinth and spongiotrophoblast layers and an increase in the giant cell layer. However, it should be noted that the DES concentration necessary to achieve a half-maximal inhibition of ERR activities $(1-10 \mu \mathrm{M}$ range, depending on the assay) is elevated compared with its ER-activating potential (nanomolar) (Kuiper et al. 1997). In another study, DES was independently confirmed to bind to all three ERRs but did not modify any of the receptors' transcriptional effects in cell-based assays (Coward et al. 2001), which could reflect cell-specific differences in the action of this compound. 
Tamoxifen (TAM) and its derivative 4-OH tamoxifen (4-OHT)

Coward et al. (2001) also show that TAM and its derivative 4-OHT disrupt the interactions between ERR $\beta$ or ERR $\gamma$ and a SRC-1-originating peptide in vitro. TAM is a selective ER modulator (SERM), and as such displays estrogenic or antiestrogenic actions according to the target tissue (see Cosman \& Lindsay 1999, Lonard \& Smith 2002 for reviews). In particular, TAM acts as an estrogen antagonist in the mammary gland and is clinically used for the treatment of breast cancer. In cell-based assays, only 4-OHT, but not TAM, acts as an antagonist and only vis-à-vis ERR $\gamma$ (Coward et al. 2001). 3D structure analysis of ERR $\gamma$ predicts that 4-OHT could be fitted into its ligandbinding cavity only if one assumes an antagonist conformation of the LBD (Greschik et al. 2002). Again a micromolar range is necessary to obtain half-maximal inhibition in transcriptional assay (Coward et al. 2001) whereas nanomolar concentrations deactivate ER $\beta$ (Kuiper et al. 1997). This micromolar concentration could still be pharmacologically relevant given the doses administered in breast cancer treatment. Along this line, a recent publication has documented a correlation of expression between $\mathrm{ER} \alpha$ and $\mathrm{ERR} \gamma$ in breast cancer patients (Ariazi et al. 2002). Although performed on a low number of samples, this study proposed ERR $\gamma$ as a favorable prognostic factor for breast tumor outcome. Altogether this could also suggest that some of the antitumor effects of TAM might be mediated by ERR $\gamma$. This hypothesis is to be tested, as it remains to be investigated whether ER and ERR $\gamma$ share target genes that can be regulated by $4-\mathrm{OHT}$. It will be also of the utmost importance to define the role of ERR $\gamma$ in cellular proliferation in the context of breast cancer.

\section{Conclusion}

Orphan ERRs have been suggested to interfere with estrogen signaling at various levels. It could therefore be expected that compounds displaying estrogen agonist or antagonist activities should also regulate ERR transcriptional activities. Inverse agonists of ERR $\beta / \gamma$ have been identified. Although the in vivo effects of DES and 4-OHT on ERR $\beta / \gamma$ remain to be documented, these discoveries, taken together with the availability of ERR $\gamma$ 's 3D structure, offer promising perspectives in the pharmacology of these receptors. In contrast, no ERR $\alpha$-interacting molecule has been identified to date that is relevant in cell-based assays (Coward et al. 2001). Expression of this receptor in human breast tumor was recently shown to be inversely correlated to estrogen responsiveness (Ariazi et al. 2002). In contrast to $\operatorname{ERR} \gamma, \operatorname{ERR} \alpha$ has thus been proposed as an unfavorable breast tumor marker which may activate estrogen-responsive targets in an estrogen-independent manner (as has been shown for the pS2 gene). Estrogen-unresponsive breast tumors often appear as relapse after a period of remission following 4-OHT treatment. These tumors represent a crucial problem, since per definition no antiestrogen-based treatment can be efficient. Confirming the expression of ERR $\alpha$ in these tumors, together with determining its effects on cell proliferation, could therefore lead to the proposal of ERR $\alpha$ as a new therapeutic target to design treatments against estrogen-independent tumors. This single example illustrates the importance of finding a regulator of the activity of ERR $\alpha$. In other words, ERR $\alpha$ needs to meet a ligand, be it natural or synthetic.

\section{Acknowledgements}

Work in our laboratory is supported by grants from Association pour la Recherche sur le Cancer (ARC) and Ligue Contre le Cancer, comités Ardèche, Drôme and Loire. B H is funded by grants from Proskelia Pharmaceuticals. We are indebted to Vincent Laudet for constant support. We thank Frédéric Flamant, Pierre-Luc Bardet and Hervé Menoni for critical reading of the manuscript.

\section{References}

Ariazi EA, Clark GM \& Mertz JE 2002 Estrogen-related receptor $\alpha$ and estrogen-related receptor $\gamma$ associate with unfavorable and favorable biomarkers, respectively, in human breast cancer. Cancer Research 62 6510-6518.

Bonnelye E, Vanacker JM, Spruyt N, Alric S, Fournier B, Desbiens X \& Laudet V 1997 a Expression of the estrogen-related receptor 1 (ERR-1) orphan receptor during mouse development. Mechanisms of Development 65 71-85.

Bonnelye E, Vanacker JM, Dittmar T, Begue A, Desbiens X, Denhardt DT, Aubin JE, Laudet V \& Fournier B $1997 b$ The ERR-1 orphan receptor is a transcriptional activator expressed during bone development. Molecular Endocrinology 11 905-916.

Bonnelye E, Merdad L, Kung V \& Aubin JE 2001 The orphan nuclear estrogen receptor-related receptor alpha (ERRalpha) is 
expressed throughout osteoblast differentiation and regulates bone formation in vitro. Fournal of Cell Biology 153 971-984.

Bourguet W, Vivat V, Wurtz JM, Chambon P, Gronemeyer H \& Moras D 2000 Crystal structure of a heterodimeric complex of RAR and RXR ligand-binding domains. Molecular Cell $\mathbf{5}$ 289-298.

Chen S, Zhou D, Yang C \& Sherman M 2001 Molecular basis for the constitutive activity of estrogen-related receptor $\alpha-1$. Fournal of Biological Chemistry 276 28465-28470.

Cosman F \& Lindsay R 1999 Selective estrogen receptor modulators: clinical spectrum. Endocrine Reviews 20 418-434.

Coward P, Lee D, Hull MV \& Lehmann JM 2001 4-Hydroxytamoxifen binds to and deactivates the estrogen-related receptor gamma. PNAS 98 8880-8884.

Dehal P, Satou Y, Campbell RK, Chapman J, Degnan B, De Tomaso A, Davidson B, Di Gregorio A, Gelpke M, Goodstein DM et al. 2002. The draft genome of Ciona intestinalis: insights into chordate and vertebrate origins. Science $\mathbf{2 9 8}$ 2157-2167.

Egea PF, Mitschler A, Rochel N, Ruff M, Chambon P \& Moras D 2000 Crystal structure of the human RXR $\alpha$ ligand-binding domain bound to its natural ligand: 9-cis retinoic acid. EMBO fournal 19 2592-2601.

Forman BM, Tzameli I, Choi HS, Chen J, Simha D, Seol W, Evans RM \& Moore DD 1998 Androstane metabolites bind to and deactivate the nuclear receptor CAR-beta. Nature 395 612-615.

Giguère V 1999 Orphan nuclear receptors: from gene to function. Endocrine Reviewes $20689-725$.

Giguère V 2002 To ERR in the estrogen pathway. Trends in Endocrinology and Metabolism 13 220-225.

Giguère V, Yang N, Segui P \& Evans RM 1988 Identification of a new class of steroid hormone receptors. Nature 331 91-94.

Goodwin B, Watson MAi Kim H, Miao J, Kemper JK \& Kliewer SA 2003 Differential regulation of rat and human CYP7Al by the nuclear oxysterol receptor liver X receptor- $\alpha$. Molecular Endocrinology 17 386-394.

Greschik H, Wurtz JM, Sanglier S, Bourguet W, van Dorsselaer A, Moras D \& Renaud JP 2002 Structural and functional evidence for ligand-independent transcriptional activation by the estrogen-related receptor 3. Molecular Cell 9 303-313.

Heard DJ, Norby PL, Holloway J \& Vissing H 2000 Human ERR $\alpha$, a third member of the estrogen receptor-related (ERR) subfamily of orphan nuclear receptors: tissue-specific isoforms are expressed during development and in the adult. Molecular Endocrinology 14 382-392.

Hentschke M, Susens U \& Borgmeyer U 2002a Domains of ERRgamma that mediate homodimerization and interaction with factors stimulating DNA binding. European Fournal of Biochemistry 269 4086-4097.

Hentschke M, Susens U \& Borgmeyer U $2002 b$ PGG-1 and PERC, coactivators of the estrogen receptor-related receptor gamma. Biochemical and Biophysical Research Communications 299 872-879.

Hermans-Borgmeyer I, Susens U \& Borgmeyer U 2000 Developmental expression of the estrogen receptor-related receptor gamma in the nervous system during mouse embryogenesis. Mechanisms of Development 97 197-199.

Hong H, Yang L \& Stallcup MR 1999 Hormone-independent transcriptional activation and coactivator binding by novel orphan nuclear receptor ERR3. Fournal of Biological Chemistry 274 22618-22626.

Huss JM, Kopp RP \& Kelly DP 2002 Peroxisome proliferatoractivated receptor coactivator- 1 alpha (PGG-1 alpha) coactivates the cardiac-enriched nuclear receptors estrogen-related receptoralpha and -gamma. Identification of novel leucine-rich interaction motif within PGC-1 alpha. Fournal of Biological Chemistry 277 40265-40274.
Ichida M, Nemoto S \& Finkel T 2002 Identification of a specific molecular repressor of the nuclear coactivator PGC-1 alpha. Journal of Biological Chemistry 277 50991-50995.

Johnston SD, Liu X, Zuo F, Eisenbraun TL, Wiley SR, Kraus RJ \& Mertz JE 1997 Estrogen-related receptor $\alpha 1$ functionally binds as a monomer to extended half-site sequences including ones contained within estrogen-response elements. Molecular Endocrinology $11342-352$.

Knutti D \& Kralli A 2001 PGG-1, a versatile coactivator. Trends in Endocrinology and Metabolism 12 360-365.

Kraus RJ, Ariazi EA, Farrell ML \& Mertz JE 2002 Estrogen-related receptor alpha 1 actively antagonizes estrogen receptor-regulated transcription in MCF-7 mammary cells. Fournal of Biological Chemistry 277 24826-24834.

Kuiper GG, Carlsson B, Grandien K, Enmark E, Haggblad J, Nilsson S \& Gustafsson JA 1997 Comparison of the ligand binding specificity and transcript tissue distribution of estrogen receptors alpha and beta. Endocrinology 138 863-870.

Laudet V \& Gronemeyer H 2002 The Nuclear Receptor Factbooks. San Diego: Academic Press.

Lonard DM \& Smith CL 2002 Molecular perspectives on selective estrogen receptor modulators (SERMs): progress in understanding their tissue-specific agonist and antagonists actions. Steroids 67 $15-24$.

Lorke DE, Susens U, Borgmeyer U \& Hermans-Borgmeyer I 2000 Differential expression of the estrogen receptor-related receptor gamma in the mouse brain. Brain Research. Molecular Brain Research 77 277-280.

Lu D, Kiriyama Y, Lee KY \& Giguère V 2001 Transcriptional regulation of the estrogen-inducible $\mathrm{pS} 2$ breast cancer marker gene by the ERR family of orphan nuclear receptors. Cancer Research 61 6755-6761.

Luo J, Sladek R, Bader JA, Matthyssen A, Rossant J \& Giguère V 1997 Placental abnormalities in mouse embryos lacking the orphan nuclear receptor ERR-beta. Nature 388 778-782.

McKenna NJ, Lanz RB \& O’Malley BW 1999 Nuclear receptor coregulators: cellular and molecular biology. Endocrine Reviews 20 321-344.

Miller C \& Sassoon DA 1998 Wnt-7a maintains appropriate uterine patterning during the development of the mouse female reproductive tract. Development 125 3201-3211.

Miller C, Degenhardt K \& Sassoon DA 1998 Fetal exposure to DES results in de-regulation of $\mathrm{Wnt7}$ a during uterine morphogenesis. Nature Genetics 20 228-230.

Parr BA \& McMahon AP 1998 Sexually dimorphic development of the mammalian reproductive tract requires Wnt-7a. Nature 395 $707-710$.

Pettersson K, Svensson K, Mattsson R, Carlsson B, Ohlsson R \& Berkenstam A 1996 Expression of a novel member of estrogen response element-binding nuclear receptors is restricted to the early stages of chorion formation during mouse embryogenesis. Mechanisms of Development 54 211-223.

Puigserver P, Wu Z, Park CW, Graves R, Wright M \& Spiegelman BM 1998 A cold-inducible coactivator of nuclear receptors linked to adaptive thermogenesis. Cell 92 829-839.

Renaud JP, Harris JM, Downes M, Burke LJ \& Muscat GE 2000 Structure-function analysis of the Rev-erbA and RVR ligand-binding domains reveals a large hydrophobic surface that mediates corepressor binding and a ligand cavity occupied by side chains. Molecular Endocrinology 14 700-717.

Repa JJ \& Mangelsdorf DJ 2000 The role of orphan nuclear receptors in the regulation of cholesterol homeostasis. Annual Review of Cell and Developmental Biology 16 459-481.

Schreiber SN, Knutti D, Brogli K, Uhlmann T \& Kralli A 2003 The transcriptional coactivator PGC-1 regulates the expression and activity of the orphan nuclear receptor estrogen-related 
receptor alpha (ERRalpha). Fournal of Biological Chemistry 278 9013-9018.

Sladek R, Bader JA \& Giguère V 1997 The orphan nuclear receptor estrogen-related receptor $\alpha$ is a transcriptional regulator of the human medium-chain acyl coenzyme A dehydrogenase gene. Molecular and Cellular Biology 17 5400-5409.

Tremblay GB, Kunath T, Bergeron D, Lapointe L, Champigny C, Bader JA, Rossant J \& Giguère V 2001 Diethylstilbestrol regulates trophoblast stem cell differentiation as a ligand of orphan nuclear receptor ERR beta. Genes and Development 15 833-838.

Tzameli I, Pissios P, Schuetz EG \& Moore DD 2000 The xenobiotic compound 1,4-bis[2- (3,5-dichloropyridyloxyl)] benzene is an agonist ligand for the nuclear receptor CAR. Molecular and Cellular Biology 20 2951-2958.

Vanacker JM, Delmarre C, Guo X \& Laudet V 1998 Activation of osteopontin promoter by the orphan nuclear receptor Estrogen Receptor Related alpha. Cell Growth and Differentiation 9 1007-1014.

Vanacker JM, Pettersson K, Gustafsson JA \& Laudet V 1999a Transcriptional targets shared by estrogen receptor-related receptors (ERRs) and estrogen receptor (ER) alpha, but not by ERbeta. EMBO fournal 18 4270-4279.

Vanacker JM, Bonnelye E, Chopin-Delannoy S, Delmarre C, Cavailles V \& Laudet V $1999 b$ Transcriptional activities of the orphan nuclear receptor ERR alpha (estrogen receptor-related receptor-alpha). Molecular Endocrinology 13 764-773.
Vega RB \& Kelly DP 1997 A role for estrogen-related receptor alpha in the control of mitochondrial fatty acid beta-oxidation during brown adipocyte differentiation. Fournal of Biological Chemistry 272 31693-31699.

Xie W, Hong H, Yang NN, Lin RJ, Simon CM, Stallcup MR \& Evans RM 1999 Constitutive activation of transcription and binding of coactivator by estrogen-related receptors 1 and 2 . Molecular Endocrinology 13 2151-2162.

Yang C \& Chen S 1999 Two organochlorine pesticides, toxaphene and chlordane, are antagonists for estrogen-related receptor $\alpha-1$ orphan receptor. Cancer Research 59 4519-4524.

Yang C, Zhou D \& Chen S 1998 Modulation of aromatase expression in the breast tissue by ERR $\alpha-1$ orphan receptor. Cancer Research 58 5695-5700.

Yang N, Shigeta H, Shi H \& Teng CT 1996 Estrogen-related receptor, hERR1, modulates estrogen receptor-mediated response of human lactoferrin gene promoter. Foumal of Biological Chemistry 271 5795-5804.

Zhang Z \& Teng CT 2000 Estrogen receptor-related receptor $\alpha 1$ interacts with coactivator and constitutively activates the estrogen response elements of the human lactoferrin gene. Fournal of Biological Chemistry 275 20837-20846.

Received 18 April 2003

Accepted 31 July 2003 